\title{
Cytochrome P450 Epoxygenase CYP2J2 G-50T Polymorphism is an Independent Genetic Prognostic Risk Factor and Interacts with Smoking Cessation After Index Premature Myocardial Infarction
}

\author{
Ping-Yen Liu ${ }^{1,2}$, Yi-Heng Li ${ }^{1}$ and Jyh-Hong Chen ${ }^{1}$ \\ ${ }^{1}$ Division of Cardiology, Departments of Internal Medicine, \\ 2Institute of Clinical Medicine, National Cheng Kung University Hospital, Tainan
}

Taiwan

\section{Introduction}

Cytochrome P450 epoxygenases metabolize arachidonic acid to epoxyeicosatrienoic acids (EETs). One human cytochrome P450 enzyme, CYP2J2, is abundantly expressed in coronary artery endothelial and smooth muscle cells, and in cardiac myocytes (Wu et al., 1996; Imig, 2000). One of the primary products of the NADPH-dependent epoxidation of arachidonic acid by CYP2J2 is the production of 11, 12-EET. This eicosanoid has potential antiinflammatory effects by inhibiting endothelial nuclear factor- B, a transcription factor associated with the induction of many pro-inflammatory gene products in the vasculature (Imig, 2000; Node et al., 1999). Other EETs, including 5,6-, 8,9-, 11,12-, and 14,15-EETs have important vasodilatation properties via mechanism of smooth muscle cells relaxation (Fang et al., 2002; Pinto et al., 1987; Spieker \& Liao, 2005; Liu et al., 2006). More recently, the additional vascular protective effects of EETs, including anti-thrombotic, antimigratory, antioxidant, and antiapoptotic effects, have also been observed (Gauthier et al., 2004; Sun et al., 2002).

Recently, a novel genetic variant G-50T of this novel gene CYP2J2 was found to be associated with coronary artery disease (CAD) (Spieker et al., 2004). This mutation could functionally result in the loss of binding of the Sp1 transcription factor to the CYP2J2 promoter and a decreased activity in CYP2J2 promoter. The plasma concentrations of stable EETs metabolites were also lower in individuals with the G-50T polymorphism. However, the role of this novel gene variant in myocardial infarction (MI), especially premature MI, is still not well investigated.

Of the common environmental factors known to be associated with risk of acute MI, smoking is widely acknowledged to make a major contribution (Manson et al., 1992; Teng et al., 1994). Smoking can disturb lipoprotein metabolism by increasing insulin resistance and lipid intolerance, and is implicated in the production of small dense low-density lipoprotein (Craig et al., 1989; Eliasson et al., 1997; Barua et al., 2002). The smoking-associated risk of MI 
has been reported to be greater in subgrouping subjects with several genetic variants background (Li et al., 2002; Liu et al., 2005; Humphries et al., 2002).

We thus hypothesized that those who with the $\mathrm{T}$ allele may have higher inflammatory status, and thus have higher risk for plaque rupture or occurrence of MI, especially at a younger age. We also speculated that there should be an additive interaction between the effect of smoking behavior and the genetic variation for the onset of premature MI.

Smoking cessation could gradually improve the endothelial function and fibrinolytic status (Tsiara et al., 2003). However, successful cessation of smoking after MI and its interaction with this candidate gene for the subsequent events after index MI was still undefined. Thus, we hypothesized that premature MI patients carrying genetic polymorphism, especially genetic variant G-50T of this novel gene CYP2J2, might have a higher risk for subsequent coronary events. In addition, smoking cessation might interact with these gene variations for the prognosis after patients' index MI in Taiwan.

\section{Methods}

\subsection{Study subjects}

\subsubsection{Study population}

We enrolled 200 patients (mean age $42.2 \pm 2.5$ years; $84 \%$ men) with documented MI onset prior to age of 45 years. The patients were recruited after their first MI. Diagnosis of MI was based on ischemic chest symptoms, typical electrocardiographic changes and elevation of serum creatine kinase and its $\mathrm{MB}$ isoenzyme, when more than twice the upper level of normal. Coronary angiography was performed using the Judkin's method within 2 weeks after the onset of symptoms. Coronary stenosis is defined as $\geq 50 \%$ diameter narrowing.

\subsubsection{Control population}

The control group was recruited by sex-matched 200 patients (mean age $42.5 \pm 2.1$ years) from consecutive subjects admitted to our hospital for routine health examinations. They did not show any clinical or electrocardiographic evidence of MI or CAD. They also had no history of cerebrovascular disease or peripheral arterial disease. Written informed consents were obtained from all patients and this study was in agreement with guidelines approved by the research committee of National Cheng-Kung University Hospital.

\subsubsection{Background of population}

All patients and controls included in this study are Han Chinese/Taiwanese from the same geographic area. The demographic data and the presence of traditional coronary risk factors, including hypertension, diabetes mellitus, smoking and serum cholesterol, were collected from all study participants.

\subsubsection{Data collection \& history recording}

For patients with MI, these data were taken from the medical records at the time of admission for acute MI; for control subjects, they were collected at the time of hospital admission for routine health examinations. They were considered to have hypertension if 
elevated blood pressure (>140/90 $\mathrm{mmHg}$ ) were measured on 3 occasions or if they were already being treated with anti-hypertensive agents. They were defined as having diabetes mellitus (DM) if they had a fasting blood glucose level $>110 \mathrm{mg} / \mathrm{dl}$ or were already being treated for DM. All study participants were classified as either smokers (including current or ex-smokers) or non-smokers. The total cholesterol level was determined at the beginning of the study.

\subsubsection{Blood collection}

The blood sampling time in the study group was at least 2 weeks after the onset of acute MI. In the control group, the blood samples were taken during coronary angiography study. All patients with impaired renal function, malignancy, connective tissue disease or chronic inflammatory disease were excluded. The blood samples were drawn into a 5-ml EDTA glass tube and centrifuged at $2200 \mathrm{~g}$ for 15 minutes to separate the plasma contents. The buffy coat after centrifugation was obtained and deoxyribonucleic acid (DNA) in each sample was isolated by the method we used before (Liu et al., 2007). The DNA samples were stored at -70 degree $C$ until use.

\subsubsection{Genomic amplification by PCR}

Patient's DNA was isolated from the whole-blood samples by the phenol-chloroform extraction method. A 273-bp promoter region proximal to the transcriptional start site was amplified with primers described previously (King et al., 2002). The sequence products were resolved on an ABI 377 automated sequencer. The promoter polymorphism G-50T was verified by direct sequencing. The numbering of the polymorphisms refers to the GenBank sequence AF272142 (accession number).

\subsubsection{Functional EET analysis}

Eicosanoids were extracted from plasma samples 3 times with ethyl acetate after acidification with acetic acid. After evaporation, saponification with $0.4 \mathrm{~N} \mathrm{KOH}$ in methanol, and reextraction, concentrations of the stable EETs metabolite 14,15-dihydroxyeicosatrienoic acid (DHET) were determined by an ELISA kit (Detroit R\&D) (Liu et al., 2007; Spieker et al., 2004).

\subsubsection{Smoking habits definition}

Individuals were classified according to their smoking status; a current smoker was defined as any person who smoked regularly (at least one cigarette per day and/or one cigar or one pipe per week). Subjects who had smoked at least one cigarette per day and/or one cigar or one pipe per week in the past were classified as former smokers. Never smokers were those who had never smoked any tobacco product regularly. Subjects were considered to have achieved smoking cessation if they were reported non-smoking from the quitting day until the end of the 6-month period.

\subsubsection{Follow-up study}

Patients received regular follow-up care in our cardiology ward or clinics for at least 6 months with a maximum of 13 years or until occurrence of one of the following coronary events: recurrent angina pectoris, non-fatal MI, or cardiac death. Recurrent angina pectoris 
was defined as recurrent chest pain with ischemic ECG changes lasting >10 min despite antiangina therapy. Diagnosis of recurrent MI was the same as for index MI (see Study population). Cause of death was determined from hospital records. In this study, the followup data were available for a total of $162(95.3 \%)$ premature MI patients. Eight patients $(4.7 \%)$ were not available for follow-up. The reasons included: $3(1.8 \%)$ patients moved back to their primary residency region and we were unable to follow-up; $3(1.8 \%)$ patients died of non-cardiovascular events, including two $(1.2 \%)$ in traffic accidents and one $(0.6 \%)$ by suicide; two $(1.2 \%)$ patients were lost or changed their telephone numbers without detailed medical records. Those event-free patients who we were unable to follow-up completely were included in the event-free group. Their follow-up periods were defined between the index MI and their last clinic visit.

\subsubsection{Statistical analysis}

Data on age and cholesterol levels were presented as mean value \pm standard deviation (SD). The values of DHET were presented as median \pm SD. The difference between the groups was analyzed by the unpaired Student's $t$ test. The differences in the frequencies of smoking, hypertension, hyperlipidemia, diabetes mellitus, and CYP2J2 G-50T genotypes were analyzed by Fisher's exact test. $\chi^{2}$ analyses were used to test deviations of genotype distribution from Hardy-Weinberg equilibrium and to determine allele or genotype frequencies between patients and control groups. The risk factors that appear to be possible significant predictors $(\mathrm{p}<0.05)$ in the single-variant analyses were included in the multiple logistic regression analyses. Multivariate analyses were conducted with multiple logistic regression methods, and adjusted estimations of conditioned relative risk and 95\% confidence intervals (CIs) were done. The Kaplan-Meier method (log-rank test) was applied in subsequent event-free analysis. All statistical analyses were performed using SPSS Advanced Statistics 13.0 for Window. In this study, a value of $\mathrm{p}<0.05$ was taken to be statistical significance.

\section{Results}

\subsection{Comparison of traditional CAD risk factors between $\mathrm{MI}$ and control groups}

We compared the control and premature MI group for traditional CAD risk factors, including hypertension, diabetes mellitus, smoking and serum cholesterol levels (Table 1).

\begin{tabular}{lll}
\hline Characteristics & Control $(\mathrm{n}=200)$ & Premature MI $(\mathrm{n}=200)$ \\
\hline Age (yrs) & $42.5 \pm 2.1$ & $42.2 \pm 2.1$ \\
Men/Women & $167 / 33$ & $168 / 32$ \\
Systemic hypertension $(\%)$ & $46(23.0)$ & $60(30.0) \dagger$ \\
Diabetes mellitus $(\%)$ & $9(4.5)$ & $26(13.0)^{*}$ \\
Smoker $(\%)$ & $89(44.5)$ & $154(77.0)^{*}$ \\
Total cholesterol (mg/dL) & $182 \pm 37.5$ & $210 \pm 34.5$ \\
Triglycerides (mg/dL) & $135 \pm 32.1$ & $136 \pm 30.8$ \\
HDL cholesterol (mg/dL) & $46 \pm 10.5$ & $41 \pm 10.1$ \\
LDL cholesterol $(\mathrm{mg} / \mathrm{dL})$ & $120 \pm 29.3$ & $128 \pm 21.5$ \\
\hline
\end{tabular}

Data are presented as number $(\%)$ of patients or mean \pm standard deviation. HDL $=$ high-density lipoprotein; $\mathrm{LDL}=$ low-density lipoprotein; $\mathrm{MI}=$ myocardial infarction. *: $\mathrm{p}<0.001 ; \mathrm{\dagger}$ : $\mathrm{p}<0.01$.

Table 1. Clinical characteristics of study subjects 
There were no significant differences in the age between these 2 groups $(p=0.890)$. The frequency of smoking $(p<0.001)$, diabetes mellitus $(p<0.001)$ and hypertension $(p<0.01)$ were significantly higher in premature MI patients. However, the traditional CAD risk factor such as total cholesterol level was similar between 2 groups.

\subsection{Distribution of CYP2J2 G-50T genotypes}

Table 2 shows the distribution of CYP2J2 G-50T genotype in both premature MI patients and control subjects. The frequency of the T allele was significantly higher in the premature MI than the control group (16.0\% vs. $12.0 \%$, p<0.01; odds ratio (OR) $2.15,95 \%$ [CI] 1.30 to 6.80$)$. There was a significantly higher prevalence of the $\mathrm{T}$ allele genotype (GT+TT) among patients with premature MI in comparison to the control subjects $(28.0 \%$ vs. $22.0 \%$; OR 2.0 , $95 \%[\mathrm{CI}] 1.3$ to $6.8, \mathrm{p}=0.01)$. The distributions of genotype in both the premature MI group and control group were compatible with the Hardy-Weinberg equilibrium.

\begin{tabular}{lllll}
\hline & Control $(\mathrm{n}=200)$ & Premature MI $(\mathrm{n}=200)$ & OR $(95 \% \mathrm{CI})$ & P value \\
\hline TT & $4(2.0)$ & $8(4.0)$ & & \\
GT & $40(20.0)$ & $48(24.0)$ & & \\
TT+GT & $44(22.0)$ & $56(28.0)$ & $2.0(1.3-6.8)$ & 0.01 \\
GG & $156(78.0)$ & $144(72.0)$ & & \\
T allele frequency & 0.12 & 0.16 & & 0.01 \\
\hline
\end{tabular}

Data are presented as number $(\%)$ of patients. $\mathrm{CI}=$ confidence interval; $\mathrm{GG}=$ homozygous $\mathrm{G}$ allele of CYP2J2 G-50T gene; GT = heterozygous allele of CYP2J2 G-50T gene; $\mathrm{MI}=$ myocardial infarction; $\mathrm{TT}=$ homozygous $\mathrm{T}$ allele of CYP2J2 G-50T gene; OR = odds ratio.

Table 2. Frequency of genotypes of CYP2J2 G-50T gene in control subjects and patients with premature myocardial infarction

\subsection{Identification of independent risk factors of MI}

Table 3 shows the results of multiple logistic regression analysis for identifying the independent risk factors of premature MI. Hypertension, DM, smoking and CYP2J2 genotype were all used as independent variables. Multiple logistic regression analysis showed that the T allele was an independent risk factor (OR 1.78, 95\% CI 1.12 to $6.40, \mathrm{p}=0.02$ ), as well as smoking (OR 3.05, 95\% CI 1.55 to 7.25, p<0.01), diabetes mellitus (OR 3.24, 95\% CI 1.22 to 6.55, $\mathrm{p}<0.01$ ) and hypertension (OR 1.95, 95\% CI 1.13 to 5.73, $\mathrm{p}<0.01$ ) for the premature onset of MI.

\begin{tabular}{llll}
\hline & OR for MI & $95 \% \mathrm{CI}$ & P value \\
\hline Smoking & 3.05 & $1.55-7.25$ & $<0.01$ \\
Diabetes mellitus & 3.24 & $1.22-6.55$ & $<0.01$ \\
Hypertension & 1.95 & $1.13-5.73$ & $<0.01$ \\
CYP2J2 G-50T polymorphism & 1.78 & $1.12-6.40$ & 0.02 \\
\hline
\end{tabular}

$\mathrm{CI}=$ confidence interval; $\mathrm{GG}=$ homozygous $\mathrm{G}$ allele of CYP2J2 G-50T gene; $\mathrm{GT}=$ heterozygous allele of CYP2J2 G-50T gene; $\mathrm{MI}=$ myocardial infarction; $\mathrm{TT}$ = homozygous $\mathrm{T}$ allele of CYP2J2 G-50T gene; $\mathrm{OR}=$ odds ratio.

Table 3. Risk factors of premature myocardial infarction identified by multiple logistic regression analysis 
Moreover, there was a synergistic effect between smoking and T allele of CYP2J2 genotype on the occurrence of MI. (Table 4.) Among patients who did not smoke, the T allele was associated with a higher risk of young MI (OR 1.43, 95\% CI 1.2 to 6.2). Smoking carrier with the $\mathrm{G}$ allele was associated with a 3-fold higher risk for premature MI (OR 3.78, 95\% CI 3.3 to 10.6). Furthermore, smoking carriers of the T allele of CYP2J2 allele had a significantly 5.6fold higher risk of premature MI (OR 5.55, 95\% CI 4.3 to 13.7) when compared with nonsmoking and $\mathrm{G}$ allele genotype carriers.

\begin{tabular}{lllllc}
\hline Smoking & $\begin{array}{l}\text { CYP2J2 G-50T } \\
\text { genotype }\end{array}$ & Control $(\mathrm{n}=200)$ & $\begin{array}{l}\text { Premature MI } \\
(\mathrm{n}=200)\end{array}$ & OR & 95\% CI \\
\hline No & GG & 87 & 36 & 1 & \\
No & GT+TT & 24 & 10 & 1.43 & $1.2-6.2$ \\
Yes & GG & 69 & 108 & 3.78 & $3.3-10.6$ \\
Yes & GT+TT & 20 & 46 & 5.55 & $4.3-13.7$ \\
\hline
\end{tabular}

Data are presented as number of patients. $\mathrm{CI}=$ confidence interval; $\mathrm{GG}=$ homozygous $\mathrm{G}$ allele of CYP2J2 G-50T gene; GT = heterozygous allele of CYP2J2 G-50T gene; $\mathrm{MI}=$ myocardial infarction; $\mathrm{TT}=$ homozygous T allele of CYP2J2 G-50T gene; OR = odds ratio

Table 4. Association between smoking and CYP2J2 G-50T genotype on premature myocardial infarction

\subsection{Functional analysis of EET metabolites}

To further investigate the functional role of the G-50T polymorphism, we measured the plasma concentrations of the major CYP2J2-dependent epoxidation product from arachidonic acid. Given the instability of the primary products, EETs, concentration of the stable metabolite 14,15-DHET was determined after extraction from plasma samples. Median DHET plasma concentrations were significantly lower in samples from premature MI subjects with the G-50T polymorphism when compared with G allele individuals (6.2 \pm $1.2 \mathrm{ng} / \mathrm{mL}$ vs. $10.8 \pm 2.5 \mathrm{ng} / \mathrm{mL} ; p=0.025)$. Among premature MI subjects, the median DHET plasma concentrations were significantly lower among smoking carriers with the G$50 \mathrm{~T}$ polymorphism $(3.3 \pm 1.0 \mathrm{ng} / \mathrm{mL}$ vs. $6.8 \pm 1.3 \mathrm{ng} / \mathrm{mL} ; p=0.001)$. However, this effect was not significant for subjects without gene variation ( $G$ allele carriers) $(10.2 \pm 1.3 \mathrm{ng} / \mathrm{mL}$ vs. $10.8 \pm 2.4 \mathrm{ng} / \mathrm{mL} ; p=0.18$ ). (Fig 1$)$

Median DHET plasma concentrations were significantly lower in samples from premature MI subjects with the G-50T polymorphism when compared with G allele individuals. Among premature MI subjects, the median DHET plasma concentrations were significantly lower among smoking carriers with the G-50T polymorphism. However, this effect was not significant for subjects without gene variation (G allele carriers). Median DHET levels were significantly lower among CYP2J2 G-50T polymorphism compared with G allele individuals. The median DEHT levels were significantly lower among smoking carriers with $\mathrm{T}$ allele subjects, but not among $\mathrm{G}$ allele ones. DHET = dihydroxyeicosatrienoic acid; $\mathrm{MI}=$ myocardial infarction. 


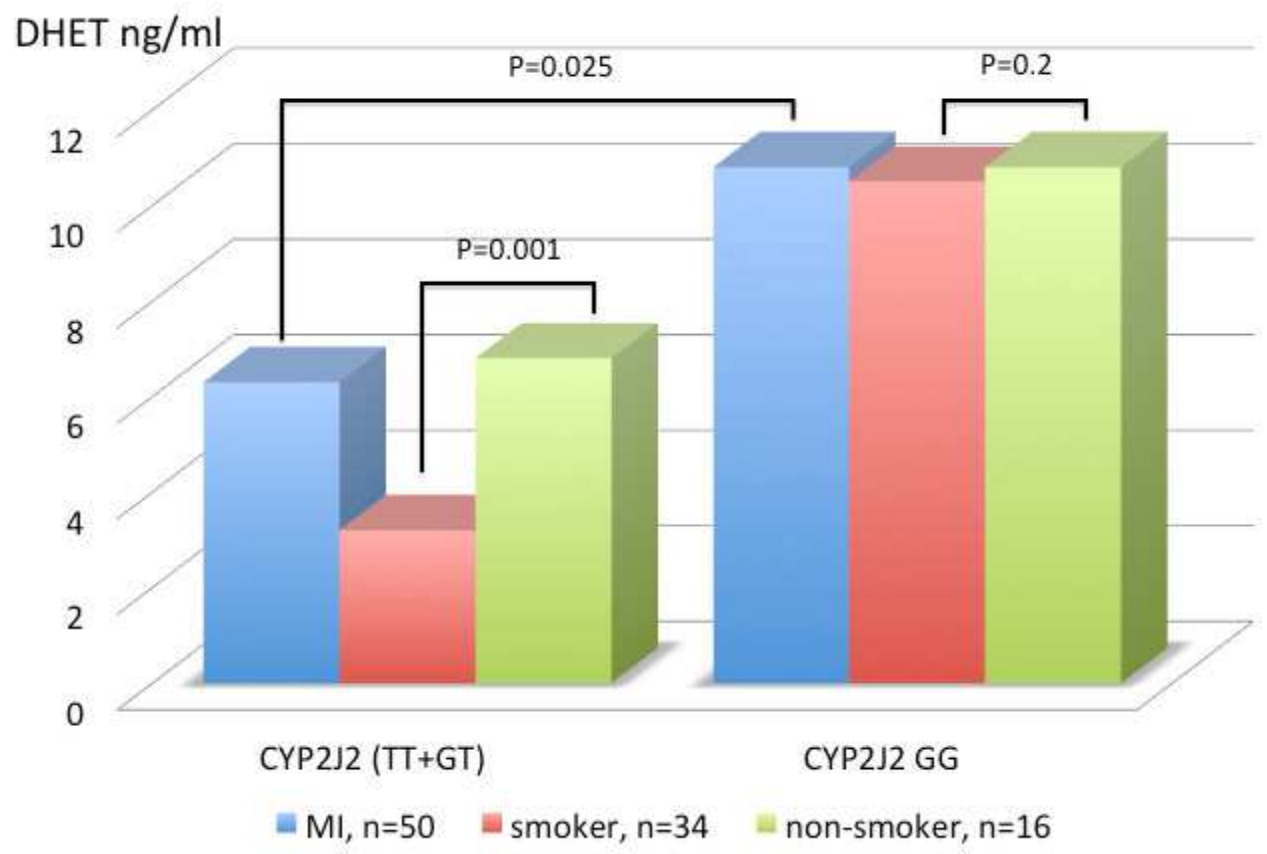

Fig. 1. Plasma concentrations of the 14, 15-dihydroxyeicosatrienoic acid (DHET), a major CYP2J2-dependent epoxidation product from arachidonic acid among premature myocardial infarction subjects.

\subsection{The follow-up clinical and angiographic characteristics analyses}

During a mean period of 4.43 years (from 0.5 to 13 years) follow-up, cardiac events occurred in $48(28.2 \%)$ patients, including four $(2.4 \%)$ with cardiac death, $24(14.1 \%)$ with recurrent MI, and $20(11.7 \%)$ with recurrent angina pectoris. The baseline and the available follow-up clinical and angiographic characteristics are shown in Table 5.

With similar mean follow-up periods, most of the clinical manifestations and treatment regimens were no different before and after follow-up in both groups that with-event and without-event, except that usage frequencies of both angiotensin-converting enzyme inhibitors (ACEI) and statin were higher after follow-up in both groups $(\mathrm{P}<0.05$, compared with their baseline data). Under these therapeutic profiles, patients' blood pressures and fasting sugar levels were also similar in both groups after follow-up. Almost $92 \%$ of our follow-up subjects received catheterization study. The prevalence distribution of the culprit coronary artery lesion changed among patients receiving follow-up coronary angiography (Table 5).

During the first catheterization study, most $(48 / 84,57.1 \%)$ patients had the culprit lesion located in the left anterior descending artery, followed by a right coronary artery lesion. However, during the late angiographic study, 31.3\% of the initial culprit lesions regressed, while $33.8 \%$ of the new De novo lesions became culprit ones. 


\begin{tabular}{|c|c|c|c|c|c|c|}
\hline & \multicolumn{3}{|c|}{ With cardiac events $(n=48,30.0 \%)$} & \multicolumn{3}{|c|}{ Without cardiac events $(\mathrm{n}=114,70.0 \%)$} \\
\hline & $\begin{array}{l}\text { Initial } \\
\text { treatment }\end{array}$ & $\begin{array}{l}\text { Final } \\
\text { treatment }\end{array}$ & P value & $\begin{array}{l}\text { Initial } \\
\text { treatment }\end{array}$ & $\begin{array}{l}\text { Final } \\
\text { treatment }\end{array}$ & $P$ value \\
\hline Hypertension & $29(60.4)$ & $31(64.5)$ & 0.14 & $36(31.5)$ & $38(33.3)$ & 0.15 \\
\hline $\begin{array}{l}\text { Diabetes } \\
\text { mellitus }\end{array}$ & $19(39.5)$ & $21(43.8)$ & 0.08 & $20(17.5)$ & $28(24.5)$ & 0.06 \\
\hline Smoking & $40(83.3)$ & $32(66.7)$ & 0.04 & $100(87.7)$ & $43(37.7)$ & 0.01 \\
\hline $\begin{array}{l}\text { Total } \\
\text { cholesterol, } \\
\mathrm{mg} / \mathrm{dL}\end{array}$ & $204 \pm 33.5$ & $208 \pm 32.7$ & 0.24 & $207 \pm 36.1$ & $207 \pm 40.7$ & 0.36 \\
\hline $\begin{array}{l}\text { HDL- } \\
\text { cholesterol, } \\
\mathrm{mg} / \mathrm{dL}\end{array}$ & $42 \pm 10$ & $44 \pm 11$ & 0.38 & $43 \pm 9$ & $44 \pm 12$ & 0.33 \\
\hline $\begin{array}{l}\text { LDL- } \\
\text { cholesterol, } \\
\mathrm{mg} / \mathrm{dL}\end{array}$ & $135 \pm 32$ & $137 \pm 40$ & 0.28 & $136 \pm 29$ & $137 \pm 39$ & 0.54 \\
\hline $\begin{array}{l}\text { Triglycerides, } \\
\mathrm{mg} / \mathrm{dL}\end{array}$ & $132 \pm 36$ & $137 \pm 56$ & 0.42 & $135 \pm 43$ & $136 \pm 56$ & 0.77 \\
\hline LVEF (\%) & $58.8 \pm 9.8$ & $57.9 \pm 10.1$ & 0.35 & $60.1 \pm 13.5$ & $59.1 \pm 11.5$ & 0.40 \\
\hline Angiography & 43 (89.9) & 44 (91.6) & 0.67 & 100 (87.7) & $94(82.4)$ & 0.58 \\
\hline PCI & $25(52.0)$ & $29(60.4)$ & 0.44 & $60(52.6)$ & 59 (51.7) & 0.38 \\
\hline CABG & $6(12.5)$ & $8(16.7)$ & 0.40 & $18(15.8)$ & $19(16.7)$ & 0.28 \\
\hline CAD & & & & & & \\
\hline Single-vessel & $24(50.0)$ & $26(54.1)$ & 0.32 & $64(56.1)$ & $60(52.6)$ & 0.85 \\
\hline LAD & 16 & 10 & & 34 & 26 & \\
\hline LCX & 3 & 7 & & 9 & 15 & \\
\hline RCA & 5 & 9 & & 21 & 19 & \\
\hline Double-vessel & $13(27.1)$ & $13(27.1)$ & 1.00 & $30(26.3)$ & $32(28.0)$ & 0.61 \\
\hline Triple-vessel & $10(20.8)$ & $8(16.7)$ & 0.44 & $22(19.2)$ & $23(20.1)$ & 0.22 \\
\hline Medications & & & & & & \\
\hline$\beta$-blocker & 19 (39.5) & $24(50.0)$ & 0.06 & $91(79.8)$ & $97(85.0)$ & 0.10 \\
\hline ACEI & $10(20.8)$ & $20(41.6)$ & 0.04 & $69(60.5)$ & $80(70.1)$ & 0.06 \\
\hline Statin & $10(20.8)$ & 18 (37.5) & 0.03 & $42(36.8)$ & $60(52.6)$ & 0.04 \\
\hline
\end{tabular}

With similar mean follow-up periods, most of the clinical manifestations and treatment regimens were no different before and after follow-up in both groups that with-event and without-event, except that usage frequencies of both angiotensin-converting enzyme inhibitors and statin were higher after followup in both groups. Under these therapeutic profiles, patients' blood pressures and fasting sugar levels were also similar in both groups after follow-up. Values are expressed as number (\%) or mean \pm SD. $\mathrm{ACEI}=$ angiotensin-converting enzyme inhibitor; $\mathrm{CABG}=$ coronary artery bypass graft surgery; $\mathrm{CAD}=$ coronary artery disease; $\mathrm{CI}=$ confidence intervals; $\mathrm{ECG}=$ electrocardiograms; $\mathrm{HDL}=$ high density lipoproteins; $\mathrm{LAD}=$ left anterior descending artery; $\mathrm{LCX}=$ left circumflex artery; $\mathrm{LDL}=$ low density lipoproteins; $\mathrm{LVEF}=$ left ventricular ejection fraction; $\mathrm{MI}=$ myocardial infarction; $\mathrm{PCI}=$ percutaneous coronary interventions; $\mathrm{RCA}=$ right coronary artery.

Table 5. The initial and follow-up clinical and angiographic characteristics of patients with premature myocardial infarction 
Compared with event-free group, subjects with event during the follow-up period had significantly higher genetic prevalence rate of $\mathrm{T}$ allele (TT+GT) (Event vs. event-free subjects: $58.3 \%$ vs. $42.1 \%$, p=0.02) as well as the whole T allele frequency (Event vs. eventfree: $42.7 \%$ vs. $29.8 \%, \mathrm{p}=0.02$ ).

\begin{tabular}{llll}
\hline CYP2J2 genotypes & With event $(\mathrm{n}=48)$ & Event-free $(\mathrm{n}=114)$ & P value \\
\hline TT+GT & $11+17(58.3)$ & $16+30(42.1)$ & 0.02 \\
GG & $20(41.6)$ & $68(60.0)$ & \\
T allele relative frequency & $41 / 96(42.7)$ & $68 / 228(29.8)$ & 0.02 \\
\hline
\end{tabular}

Compared with event-free group, subjects with event during the follow-up period had significantly higher genetic prevalence rate of $\mathrm{T}$ allele $(\mathrm{TT}+\mathrm{GT})$ as well as the whole $\mathrm{T}$ allele frequency. Values are expressed as $\mathrm{n}(\%)$.

Table 6. Frequencies of CYP2J2 G-50T genotypes in groups with or without cardiac events after index myocardial infarction

Kaplan-Meier analysis demonstrated a significantly lower probability $(23.5 \%$ vs. $34.6 \%$, logrank $\mathrm{P}=0.04$ ) of developing clinical coronary events among patients with the polymorphism of CYP2J2 promoter G-50T genotype (Fig. 2).

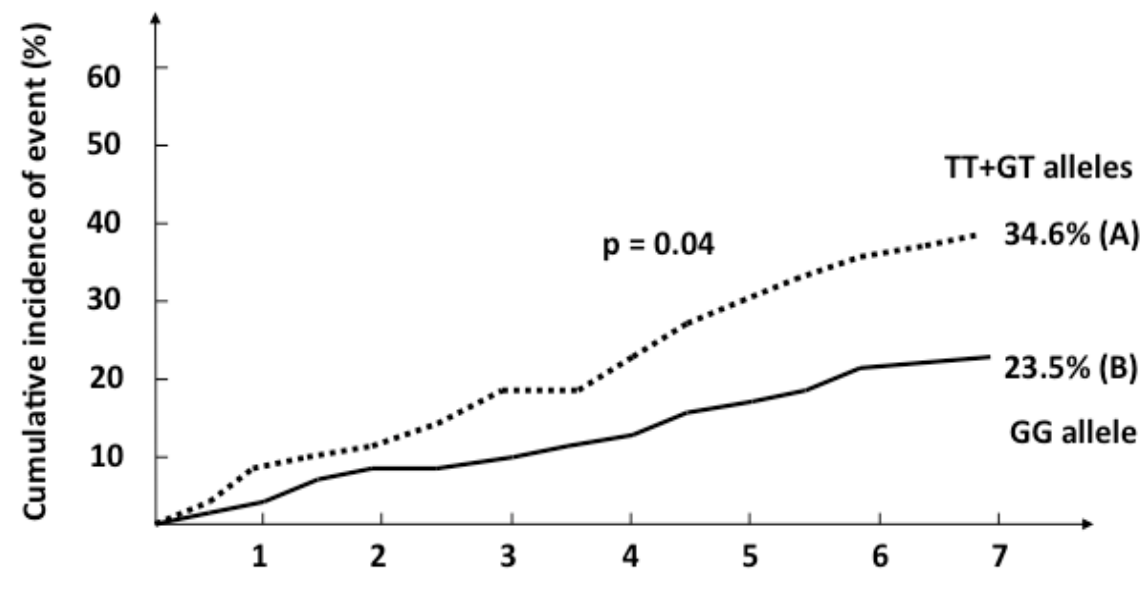

Follow-up duration (years)

Fig. 2. Kaplan-Meier survival curve for subsequent coronary events after index acute myocardial infarction for the patients carrying TT or GT allele (A) (or GG allele for (B)) at their CYP2J2 gene (after modified risk with age, diabetes mellitus, smoking, hypertension, and medication usage with ACEI or $\beta$-blockers).

For traditional risk factors, patients in event groups had significantly higher prevalence rates of DM, hypertension and initial severe Killip's status ( $>$ II) (all $\mathrm{P}<0.05$, see Table 7). The mean cholesterol level was also higher in the event group. Compared with the event group, patients without events received more medications such as ACEI, $\beta$-blocker and statin. The success rate of smoking cessation was higher in the event-free group (52.0\% vs. $19.5 \%)$. 
However, the event-free group patients received more frequent procedures of coronary bypass surgery in our MI group.

\begin{tabular}{|c|c|c|c|}
\hline & $\begin{array}{l}\text { Without cardiac } \\
\text { events } \\
(n=114,70.0 \%)\end{array}$ & $\begin{array}{l}\text { With cardiac } \\
\text { events } \\
(n=48,30 \%)\end{array}$ & $\mathrm{p}$ value \\
\hline Age (years) & $40.3 \pm 4.8$ & $39.7 \pm 4.4$ & 0.43 \\
\hline Sex (male) & $91(79.8)$ & $42(87.5)$ & 0.50 \\
\hline Family history & $23(20.1)$ & $10(20.8)$ & 0.73 \\
\hline Hypertension & $36(28.9)$ & $29(60.4)$ & $<0.01$ \\
\hline Diabetes mellitus & $20(17.5)$ & $19(39.5)$ & $<0.01$ \\
\hline Smoking & $100(87.7)$ & $42(87.5)$ & 0.77 \\
\hline Total cholesterol, mg/dL & $191.4 \pm 33.2$ & $209.0 \pm 35.3$ & $<0.01$ \\
\hline HDL-cholesterol, mg/dL & $42 \pm 11$ & $44 \pm 9$ & 0.22 \\
\hline LDL-cholesterol, mg/dL & $133 \pm 32$ & $136 \pm 30$ & 0.34 \\
\hline Triglycerides, mg/dL & $135 \pm 37$ & $138 \pm 44$ & 0.25 \\
\hline \multicolumn{4}{|l|}{ Status of MI } \\
\hline Q wave in EKG & $98(85.9)$ & $36(75.0)$ & 0.47 \\
\hline Peak CK level (U/L) & $2845 \pm 1988$ & $2975 \pm 2354$ & 0.38 \\
\hline $\operatorname{LVEF}(\%)$ & $55.4 \pm 11.5$ & $54.8 \pm 12.3$ & 0.64 \\
\hline LVEF $<45 \%$ & $26(22.8)$ & $14(29.1)$ & 0.06 \\
\hline Thrombolytic therapy & $89(78.0)$ & $36(75.0)$ & 1.00 \\
\hline Primary PTCA & 19 (16.6) & $8(16.7)$ & 1.00 \\
\hline Coronary angiography & $107(93.8)$ & 44 (91.6) & 1.00 \\
\hline PCI & $61(53.5)$ & $25(52.0)$ & 0.89 \\
\hline CABG & $18(15.8)$ & $6(12.5)$ & 0.81 \\
\hline $\mathrm{VT} / \mathrm{Vf}$ at MI & $9(7.8)$ & $4(8.3)$ & 0.91 \\
\hline Killip's classification $\geq$ II & $26(22.8)$ & $23(47.9)$ & $<0.01$ \\
\hline \multicolumn{4}{|l|}{ Medication usage after MI } \\
\hline$\beta$-blocker & $91(79.8)$ & $19(39.5)$ & $<0.01$ \\
\hline ACEI & $69(60.5)$ & $10(20.8)$ & $<0.01$ \\
\hline Statin & $42(36.8)$ & $10(20.8)$ & 0.03 \\
\hline
\end{tabular}

Patients in event groups had significantly higher prevalence rates of DM, hypertension and initial severe Killip's status (>II). The mean cholesterol level was also higher in the event group. Compared with the event group, patients without events received more medications such as ACEI, $\beta$-blocker and statin. The success rate of smoking cessation was higher in the event-free group. The event-free group patients received more frequent procedures of coronary bypass surgery in our MI group. Values are expressed as number $(\%)$ or mean $\pm \mathrm{SD}$. $\mathrm{CK}=$ creatine kinase; $\mathrm{Vf}=$ ventricular fibrillation; $\mathrm{VT}=$ ventricular tachycardia.

Table 7. Comparison between patient groups with- or without- subsequent cardiac events during follow-up period after index myocardial infarction 
Univariate Cox regression analyses of the clinical characteristics and genetic backgrounds of premature MI patients are shown in Table 8. Finally, we included the variables as DM, hypertension, smoking cessation after MI, multiple (>2-vessel) coronary disease, medical therapies with $\beta$-blockers, ACEI, or statins in traditional risk factors; and the polymorphism of CYP2J2 promoter G-50T genotype in genetic factors in the multiple logistic regression analysis. For clinical consideration, we also included factors such as treatment by thrombolysis or primary angioplasty or none into this survival analyses. That analysis showed that the polymorphism of CYP2J2 promoter G-50T genotype, DM, smoking cessation and use of ACEI were independent survival predictors (Table 9).

\begin{tabular}{lll}
\hline & Hazard ratios $(95 \% \mathrm{CI})$ & p value \\
\hline Genetic variables & & \\
CYP2J2 G-50T & $2.78(1.50-5.00)$ & $<0.01$ \\
Traditional variables & $1.59(0.94-3.08)$ & 0.07 \\
Age (>40 years-old) & $0.66(0.18-2.18)$ & 0.51 \\
Sex (male) & $0.72(0.35-1.55)$ & 0.38 \\
Family history vs. non-history & $2.09(1.39-5.05)$ & $<0.01$ \\
Systemic hypertension & $2.71(1.46-4.89)$ & $<0.01$ \\
Diabetes mellitus & $1.89(0.82-3.01)$ & 0.55 \\
Smoking behavior before MI & $0.21(0.11-0.40)$ & $<0.01$ \\
Smoking cessation after MI & $1.41(0.50-1.98)$ & 0.22 \\
Total cholesterol > 200mg/dL & $1.47(0.81-1.95)$ & 0.25 \\
Anterior MI vs. other wall & $0.68(0.36-1.30)$ & 0.25 \\
LVEF (<45\%) & $1.42(0.62-6.39)$ & 0.57 \\
Thrombolytic therapy & $1.17(0.93-8.78)$ & 0.10 \\
Primary PTCA & $0.46(0.78-4.76)$ & 0.88 \\
Coronary angiography & $0.53(0.39-2.54)$ & 0.70 \\
PCI procedure & $0.87(0.72-1.32)$ & 0.89 \\
CABG & $0.77(0.79-2.69)$ & 0.72 \\
VT/Vf at MI & $1.88(1.33-6.62)$ & $<0.01$ \\
Killip's classification $\geq$ II & $2.96(0.84-7.25)$ & 0.42 \\
Multiple (>2-vessel) disease & $2.34(1.51-3.17)$ & 0.01 \\
Medication usage after MI & $7.19(2.84-10.2)$ & 0.01 \\
Not-using $\beta$-blocker & $1.65(1.02-2.93)$ & \\
Not-using ACEI & & \\
Not-using statin & & \\
\hline
\end{tabular}

Table 8. Univariate analyses of traditional and genetic risk factors with Cox proportional hazards models for subsequent cardiac events. Values are expressed as number (\%) or mean $\pm \mathrm{SD}$. 


\begin{tabular}{lll}
\hline & Hazard ratios $(95 \% \mathrm{CI})$ & p value \\
\hline Not-using ACEI & $10.5(2.08-14.18)$ & $<0.01$ \\
Diabetes mellitus & $2.41(1.23-6.95)$ & 0.01 \\
Smoking cessation after MI & $0.33(0.15-0.81)$ & 0.01 \\
Not-using statin & $1.45(1.02-2.95)$ & 0.04 \\
CYP2J2 G-50T & $2.51(1.09-5.78)$ & 0.03 \\
Not-using $\beta$-blocker & $1.46(0.99-3.29)$ & 0.06 \\
Multiple vessel disease & $1.76(0.88-7.56)$ & 0.26 \\
Systemic hypertension & $1.57(0.84-3.57)$ & 0.32 \\
Thrombolytic therapy & $1.52(0.25-8.40)$ & 0.50 \\
LVEF <45\% & $1.34(0.87-10.56)$ & 0.55 \\
Primary PTCA & $1.08(0.80-10.12)$ & 0.43 \\
Killip's classification $\geq$ II & $1.48(0.59-8.76)$ & 0.34 \\
Age (>40 years-old) & $1.32(0.50-2.22)$ & 0.65 \\
\hline
\end{tabular}

The variables as DM, hypertension, smoking cessation after MI, multiple (>2-vessel) coronary disease, medical therapies with $\beta$-blockers, ACEI, or statins in traditional risk factors; and the polymorphism of CYP2J2 promoter G-50T genotype in genetic factors were put in the multiple logistic regression analysis. That analysis showed that the polymorphism of CYP2J2 promoter G-50T genotype, DM, smoking cessation and use of ACEI were independent survival predictors. Values are expressed as number $(\%)$ or mean $\pm \mathrm{SD}$.

Table 9. Multivariate analysis with Cox regression method assessing both traditional and genetic risk factors for subsequent cardiac events

\subsection{The modification effect and gene-environment interaction of smoking cessation}

We also analyzed the effect of smoking cessation after the smoker's index MI. We divided the smoking patients into two groups, based on their successful smoking cessation or not after the index MI and found that successful smoking cessation could improve the outcome (successful smoking cessation: event vs. event-free, $25 \%$ vs. $46.3 \%$, HR $0.26,95 \%$ CI 0.11 to 0.42; current smoking after index MI: event vs. event-free, $60 \%$ vs. $28.4 \%$, HR 3.91, $95 \%$ CI 2.37 to 8.86 ; $\mathrm{P}=0.003$ for HR difference). Gene-environment interactions were analyzed for the polymorphism of CYP2J2 promoter G-50T genotype. Among the successful smoking cessation subjects, the risk of subsequent cardiovascular events was 1.6-fold higher among the $G$ allele subgroup when compared with the $T$ allele carrying subjects. With the same genetic background as $\mathrm{T}$ genotype, their risk was also 2.1-fold higher among current smokers. However, among patients who carried the $\mathrm{G}$ allele, the current smoking behavior increased the risk to 7.2-fold higher (Fig. 3). It seems that the risk could be lower after smoking cessation, even among high-risk gene carrying patients. 


\section{Hazard ratio for CV outcome}

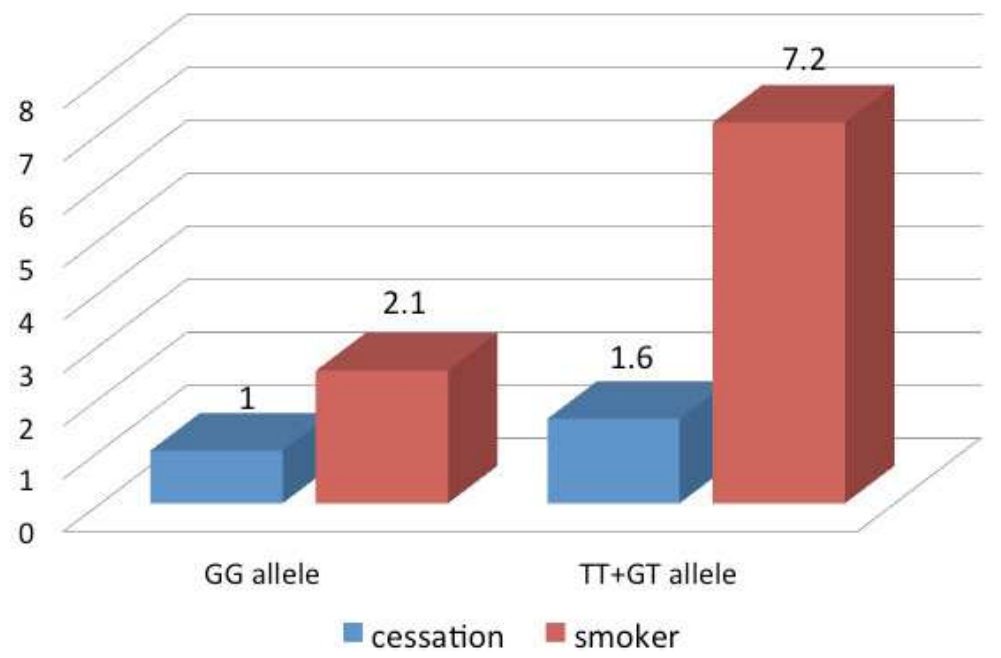

Fig. 3. Modification and interaction effects of the CYP2J2 G-50T gene polymorphism and the cessation of smoking for the risk of subsequent cardiac events

\section{Discussion}

The present study investigates the association between the polymorphism of CYP2J2 promoter G-50T genotype and the onset of premature MI in Taiwanese population. We found a higher frequency of $\mathrm{T}$ allele in patients with premature MI than in control subjects. There was a significant synergistic interaction between this polymorphism and the smoking behavior for the onset of MI at younger age in Taiwan.

\subsection{Mechanism of the association between the polymorphism of the CYP2J2 promoter G-50T genotype and premature MI}

The polymorphism of CYP2J2 promoter G-50T gene has been described among different disease status groups, including hypertension and CAD (Spieker et al., 2004; King et al., 2005). Spieker et al had demonstrated a functional relevance of this genetic variant by the method of electrophoretic mobility shift assays in human umbilical vein endothelial cells (Spieker et al., 2004). They found a functional consequence of reduced Sp1-DNA binding on transcriptional activation of the CYP2J2 gene by using transfection studies in vitro. The construction containing the wild type promoter induced a 2 -fold higher promoter activity compared with the mutant G-50T construct cells. In subjects of documented CAD, the frequency of the G-50T polymorphism was much higher. In our study, we also demonstrate that patients with CYP2J2 G-50T allele have higher possibility of premature MI. In addition, the T allele in the promoter region of CYP2J2 gene may functionally reduce EETs activities in the atherosclerotic vasculature, which was supported by the evidence of relationship between the genotype G$50 \mathrm{~T}$ and the reduced EETs activities in these MI patients. This gene-phenotype association of the G-50T mutation in this promoter region could be considered as one of the possible causes to enhance the vulnerability of the atherosclerotic plaque under stimulation. 


\subsection{The synergistic effects of the CYP2J2 G-50T genotype and smoking behavior}

In our subgroup analysis, we also demonstrate this gene-environment interaction between smoking behavior and the CYP2J2 G-50T polymorphism. Among non-smoker groups, the risk of $\mathrm{MI}$ in patients with T allele (CYP2J2 GT+TT) is significantly higher when compared with the CYP2J2 GG genotype patients (OR 1.43 and 1.0, respectively). The smoking behavior alone can increase 3-fold risk of MI in patients with lower activity of CYP2J2 GG genotype at the promoter region. However, those smokers carrying the $\mathrm{T}$ allele polymorphism had a 5.6-fold higher risk of young MI when compared with non-smoking non-carriers.

Arachidonic acid metabolites contribute to the regulation of vascular tone and therefore tissue blood flow (Imig 2000; Gauthier et al., 2004). The vascular endothelium metabolizes arachidonic acid by cytochrome P450 epoxygenases to epoxyeicosatrienoic acids or EETs. In the vasculature, EETs are key components of cellular signaling cascades that cumulate in the activation of smooth muscle potassium channels to induce membrane hyperpolarization and vascular relaxation. Smoking habit might induce the hypercoagulable state by increasing platelet aggregability and had been recognized as a potent risk factor for premature MI (Teng et al., 1994).

In current gene-phenotype functional study, we successfully demonstrated that this genetic variant could influence the active EETs metabolites concentrations among premature MI subjects. Patients carrying $\mathrm{T}$ allele at promoter region of CYP2J2 gene thus had lower median value of 14,15 EETs concentrations, which might protect their coronary vasculatures. In addition, smoking could alter the metabolites of arachidonic acid (Ye et al., 2004). This effect was observed, in our study, more significantly among CYP2J2 G-50T polymorphism carriers whom probably were more prone to the oxidative stress damage due to their impaired EETs functions. These combination effects might explain the possible mechanism for the synergistic effect of smoking behavior and the functional change of EETs activities by polymorphism with different genotypes in its promoter gene.

\subsection{Modification effects of smoking cessation and its association with gene variation on prognosis}

Smokers have twice the risk of dying of coronary heart disease or stroke, and the risk diminishes by half in the first year after cessation. After 5-15 years of smoking cessation, the risk of both stroke and heart disease drops to the level of never-smokers. Previous studies usually used the history of smoking rather than current status of smoking for analysis (Li et al., 2002; Sacks et al., 1996). Our study analyzed the influence of smoking cessation on the prognosis following MI and found that those who kept on smoking could have a higher risk for subsequent coronary events when compared with those who stopped smoking. Moreover, among patients carrying higher risk genetic background, which indicated the $T$ allele gene, the benefit was even greater from smoking cessation. It seems that a gene-environment modification relationship exists between smoking behavior and the CYP2J2 gene variation.

In fact, the smoking behavior alone is a potent risk factor for MI at a young age (Teng et al., 1994; Liu et al., 2003). Smoking, in supporting of our current in vitro and in vivo findings, can also reduce the activities of DHET and may explain partially the possible mechanism for the smoking behavior alone or its interaction with gene variation to change the CYP2J2 gene activity. Our findings also suggest that successful smoking cessation is very important and can improve the cardiovascular outcome, especially among those patients carrying high-risk genes. 


\section{Conclusion}

There was a significant association between the polymorphism of G-50T genotype in the promoter region of CYP2J2 gene and premature MI in Taiwan. Both the CYP2J2 G-50T genotype and smoking were independent risk factors for young MI population. A synergistic effect between these two risk factors for the premature onset of MI had been shown in subgroup analyses. In addition, there was a significant association between the CYP2J2 G-50T genotype and the prognosis after index premature MI. Successful smoking cessation after MI also could reduce the incidence of recurrent coronary events, especially among high-risk genetic background populations. Such findings lend credence to the concept that genetics and environment should not be viewed as independent risk factors for a particular disease; rather, environment and genetics interact with each to determine overall health.

\section{Acknowledgement}

This study was supported in part by the Multidisciplinary Center of Excellence for Clinical Trial and Research (DOH100-TD-B-111-002), Department of Health, Executive Yuan, Taiwan and by the Grant 98-2314-B-006-047-MY3 from National Science Council, Executive Yuan, Taipei, Taiwan

\section{References}

Barua, R.; Ambrose, J.; Saha, D. \& Eales-Reynolds L. (2002). Smoking is associated with altered endothelial-derived fibrinolytic and antithrombotic factors, an in vitro demonstration. Circulation, Vol. 106, pp. 905-908.

Craig, M.; Palomaki, G. \& Haddow, J. (1989). Cigarette smoking and serum lipid and lipoprotein concentrations: an analysis of published data. Br Med J, Vol. 298, pp. 784-788.

Eliasson, B.; Mero, N.; Taskinen M.; \& Smith U. (1997). The insulin resistance syndrome and postprandial lipid intolerance in smokers. Atherosclerosis, Vol. 129, pp. 79-88.

Fang, X.; Weintraub, N.; Oltman, C.; Stoll, L.; Kaduce, T.; Harmon, S.; Dellsperger, K.; Morisseau, C.; Hammock, B. \& Spector, A. (2002). Human coronary endothelial cells convert 14,15-EET to a biologically active chain-shortened epoxide. Am J Physiol Heart Circ Physiol, Vol. 283, pp. H2306-H2314.

Gauthier, K.; Falck, J.; Reddy, L. \& Campbell, W. (2004). 14,15-EET analogs: characterization of structural requirements for agonist and antagonist activity in bovine coronary arteries. Pharmacol Res; Vol. 49, pp. 515-524.

Humphries, S.; Marin, S.; Cooper, J. \& Miller, G. (2002). Interaction between smoking and the stromelysi-1 (MMP3) gene 5A/6A promoter polymorphism and risk of coronary heart disease in healthy men. Ann Hum Genet, Vol. 66, pp. 343-352.

Imig, J. (2000). Epoxygenase metabolites. Epithelial and vascular actions. Mol Biotechnol, Vol. 16, pp. 233-251. Review.

King, L.; Gainer, J.; David, G.; Dai, D.; Goldstein, J.; Brown, N. \& Zeldin, D. (2005). Single nucleotide polymorphisms in the CYP2J2 and CYP2C8 genes and the risk of hypertension. Pharmacogenet Genomics, Vol. 15, pp 7-13.

King, L.; Ma, J.; Srettabunjong, S.; Graves, J.; Bradbury, J.; Li, L.; Spiecker, M.; Liao, J.; Mohrenweiser, H. \& Zeldin, D. (2002). Cloning of CYP2J2 gene and identification of functional polymorphisms. Mol Pharmacol, Vol. 61, pp. 840-852. 
Li, Y.; Chen, J.; Tsai, W.; Chao, T.; Guo, H.; Tsai, L.; Wu, H. \& Shi, G. (2002). Synergistic effect of thrombomodulin promoter $-33 \mathrm{G} / \mathrm{A}$ polymorphism and smoking on the onset of acute myocardial infarction. Thromb Haemost, Vol. 87, pp. 86-91.

Liu, P.; Li, Y.; Chao, T.; Wu, H.; Lin, L.; Tsai, L. \& Chen, J. (2007). Synergistic effect of cytochrome P450 epoxygenase CYP2J2*7 polymorphism with smoking on the onset of premature myocardial infarction. Atherosclerosis, Vol. 195, pp. 199-206.

Liu, P.; Li, Y.; Tsai, W.; Tsai, L.; Chao, T.; Wu, H. \& Chen, J. (2005). Stromelysin-1 promoter $5 \mathrm{~A} / 6 \mathrm{~A}$ polymorphism is an independent genetic prognostic risk factor and interacts with smoking cessation after index premature myocardial infarction. J Thromb Haemost, Vol. 3, pp. 1998-2005.

Liu, P.; Tsai, W.; Lin, L.; Li, Y.; Chao, T.; Tsai, L. \& Chen, J. (2003). Time domain heart rate variability as a predictor of long-term prognosis after acute myocardial infarction. $J$ Formos Med Assoc, Vol. 102, pp. 474-479.

Manson, J.; Tosteson, H.; Ridker, P.; Satterfield, S.; Hebert, P.; O'Connor, G.; Buring, J. \& Hennekens, C. (1992). The primary prevention of myocardial infarction. $N$ Engl J Med, Vol. 326, pp. 1406-1416.

Node, K.; Huo, Y.; Ruan, X.; Yang, B.; Spiecker, M.; Ley, K.; Zeldin, D. \& Liao, J. (1999). Antiinflammatory properties of cytochrome P450 epoxygenase-derived eicosanoids. Science, Vol. 285, pp. 1276-1279.

Pinto, A.; Abraham, N. \& Mullane, K. (1987). Arachidonic acid-induced endothelialdependent relaxations of canine coronary arteries: contribution of a cytochrome P450-dependent pathway. J Pharmacol Exp Ther, Vol. 240, pp. 856-863.

Sacks, F.; Pfeffer, M.; Moye, L.; Rouleau, J.; Rutherford, J.; Cole, T.; Brown, L.; Warnica, J.; Arnold, J.; Wun, C.; Davis, B. \& Braunwald, E. (1996). The effect of pravastatin on coronary events after myocardial infarction in patients with average cholesterol levels. Cholesterol and Recurrent Events Trial investigators. N Engl J Med, Vol. 335, pp. 1001-1009.

Sun, J.; Sui, X.; Bradbury, J.; Zeldin, D.; Conte, M. \& Liao, J. (2002). Inhibition of vascular smooth muscle cell migration by cytochrome p450 epoxygenase-derived eicosanoids. Circ Res, Vol. 90, pp. 1020-1027.

Spiecker, M.; Darius, H.; Hankeln, T.; Soufi, M.; Sattler, A.; Schaefer, J.; Node, K.; Borgel, J.; Mugge, A.; Lindpaintner, K.; Huesing, A.; Maisch, B.; Zeldin, D. \& Liao, J. (2004). Risk of coronary artery disease associated with polymorphism of the cytochrome P450 epoxygenase CYP2J2. Circulation, Vol. 110, pp. 2132-2136.

Spiecker, M. \& Liao, J. (2005). Vascular protective effects of cytochrome p450 epoxygenase-derived eicosanoids. Arch Biochem Biophys, Vol.433, pp. 413-420. Review.

Teng, J.; Lin, L.; Tsai, L.; Kwan, C. \& Chen, J. (1994). Acute myocardial infarction in young and very old Chinese adults: clinical and therapeutic implications. Int J Cardiol, Vol. 44, pp. 29-36.

Tsiara, S.; Elisaf, M. \& Mikhailidis, D. (2003). Influence of smoking on predictors of vascular disease. Angiology, Vol. 54, pp. 507-530.

Wu, S.; Moomaw, C.; Tomer, K.; Falck, J. \& Zeldin, D. (1996). Molecular cloning and expression of CYP2J2, a human cytochrome P450 arachidonic acid epoxygenase highly expressed in heart. J Biol Chem, Vol. 271, pp. 3460-3468.

Ye, Y.; Liu, E.; Shin, V.; Wu, W.; Luo, J. \& Cho, C. (2004). Nicotine promoted colon cancer growth via epidermal growth factor receptor, c-Src, and 5-lipoxygenase-mediated signal pathway. J Pharmacol Exp Ther, Vol. 308, pp. 66-72. 


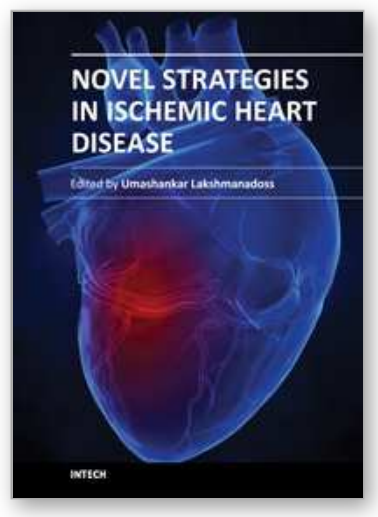

\author{
Novel Strategies in Ischemic Heart Disease \\ Edited by Dr. Umashankar Lakshmanadoss
}

ISBN 978-953-51-0184-0

Hard cover, 450 pages

Publisher InTech

Published online 29, February, 2012

Published in print edition February, 2012

The first edition of this book will provide a comprehensive overview of ischemic heart disease, including epidemiology, risk factors, pathogenesis, clinical presentation, diagnostic tests, differential diagnosis, treatment, complications and prognosis. Also discussed are current treatment options, protocols and diagnostic procedures, as well as the latest advances in the field. The book will serve as a cutting-edge point of reference for the basic or clinical researcher, and any clinician involved in the diagnosis and management of ischemic heart disease. This book is essentially designed to fill the vital gap existing between these practices, to provide a textbook that is substantial and readable, compact and reasonably comprehensive, and to provide an excellent blend of "basics to bedside and beyond" in the field of ischemic heart disease. The book also covers the future novel treatment strategies, focusing on the basic scientific and clinical aspects of the diagnosis and management of ischemic heart disease.

\title{
How to reference
}

In order to correctly reference this scholarly work, feel free to copy and paste the following:

Ping-Yen Liu, Yi-Heng Li and Jyh-Hong Chen (2012). Cytochrome P450 Epoxygenase CYP2J2 G-50T Polymorphism is an Independent Genetic Prognostic Risk Factor and Interacts with Smoking Cessation After Index Premature Myocardial Infarction, Novel Strategies in Ischemic Heart Disease, Dr. Umashankar Lakshmanadoss (Ed.), ISBN: 978-953-51-0184-0, InTech, Available from:

http://www.intechopen.com/books/novel-strategies-in-ischemic-heart-disease/cytochrome-p450-epoxygenasecyp2j2-7-polymorphism-is-an-independent-genetic-prognostic-risk-factor-a

\section{INTECH}

open science | open minds

\section{InTech Europe}

University Campus STeP Ri

Slavka Krautzeka 83/A

51000 Rijeka, Croatia

Phone: +385 (51) 770447

Fax: +385 (51) 686166

www.intechopen.com

\section{InTech China}

Unit 405, Office Block, Hotel Equatorial Shanghai

No.65, Yan An Road (West), Shanghai, 200040, China 中国上海市延安西路65号上海国际贵都大饭店办公楼 405 单元

Phone: $+86-21-62489820$

Fax: $+86-21-62489821$ 
(C) 2012 The Author(s). Licensee IntechOpen. This is an open access article distributed under the terms of the Creative Commons Attribution 3.0 License, which permits unrestricted use, distribution, and reproduction in any medium, provided the original work is properly cited. 